\title{
Air flow plays a key role in mitigating the COVID-19 airborne infection
}

\author{
yoshiyasu takefuji ${ }^{1}$ \\ ${ }^{1}$ Affiliation not available
}

November 2, 2020

\begin{abstract}
WHO guidance has incorrect recommendation in Oral health care involving AGPs. Air flow plays a key role in mitigating COVID-19 infection since airborne particles travel by air currents.

BDA criticises misreporting of WHO guidance ${ }^{1}$. The document published by WHO on 3 August advocating that 'Oral health care involving AGPs shows incorrect procedures in the wind control. According to WHO, Aerosol-generating procedures (AGPs) are widely performed worldwide in oral health care settings. AGPs are defined as any medical, dental and patient care procedure that results in the production of airborne particles $<5$ micrometres $(\mu \mathrm{m})$ in size (aerosols), which can remain suspended in the air, travel over a distance and may cause infection if they are inhaled.
\end{abstract}

SARS-CoV-2 was named after SARS by WHO on Feb. $112020^{2}$. This virus naming means that SARS-CoV2 is very similar to SARS-COV. Both SARS-CoV and SARS-CoV-2 use human ACE2 as entry receptor and human proteases as entry activators ${ }^{3,4,5}$. In other words, SARS-CoV-2 has the same transmission behavior as SARS-CoV. COVID-19 is an airborne infection disease.

In order to avoid airborne infection of COVID-19 between a patient and the dentist, it is necessary to control the air flow since airborne particles often remain suspended in the air or travel by the air currents. We need to make sure that the air flow doesn't always point towards the body in order to prevent airborne infections. WHO did not mention the air flow direction at all ${ }^{6,7}$. To prevent airborne infections, it is always necessary to keep the air flow away from the body.

In order to control the air flow, we should use vacuum cleaners against airborne viruses. A vacuum cleaner is a device that causes suction in order to remove airborne viruses travelling from infected persons. Always make sure keeping the air flow away from the body.

References:

1. BDA criticises misreporting of WHO guidance. $\quad B r$ Dent J229, $215 \quad$ (2020). https://doi.org/10.1038/s41415-020-2088-3

2.https://www.who.int/emergencies/diseases/novel-coronavirus-2019/technical-guidance/naming-thecoronavirus-disease-(covid-2019)-and-the-virus-that-causes-it 
3. Rossi, G.A., Sacco, O., Mancino, E. et al. Differences and similarities between SARS-CoV and SARSCoV-2: spike receptor-binding domain recognition and host cell infection with support of cellular serine proteases. Infection (2020).

https://doi.org/10.1007/s15010-020-01486-5

4. Sungnak, W., Huang, N., Bécavin, C. et al. SARS-CoV-2 entry factors are highly expressed in nasal epithelial cells together with innate immune genes. Nat Med 26, 681-687 (2020). https://doi.org/10.1038/s41591020-0868-6

5. Renhong Yan et al., Structural basis for the recognition of SARS-CoV-2 by full-length human ACE2, Science 27 Mar 2020: Vol. 367, Issue 6485, pp. 1444-1448 DOI: 10.1126/science.abb2762

6. World Health Organization. Infection prevention and control during health care when coronavirus disease (COVID-19) is suspected or confirmed.

https://www.who.int/publications/i/item/WHO-2019-nCoV-IPC-2020.4. Published 2020. Accessed 23 July, 2020

7. World Health Organization. Publication/Guidelines. Natural Ventilation for Infection Control in HealthCare Settings.

https://apps.who.int/iris/bitstream/handle/10665/44167/9789241547857_eng.pdf. Published 2009. Accessed 23 July, 2020. 